\title{
Effects of ultrafine particles-induced oxidative stress on Clara cells in allergic lung inflammation
}

\author{
Francesca Alessandrini*1,2, Ingrid Weichenmeier ${ }^{1}$, Erik van Miert 3 , Shinji Takenaka4 ${ }^{4}$ Erwin Karg 4,5, Cornelia Blume1, \\ Martin Mempel ${ }^{1}$, Holger Schulz ${ }^{4}$, Alfred Bernard ${ }^{3}$ and Heidrun Behrendt 1,2
}

\begin{abstract}
Background: Clara cell protein (CC16), the main secretory product of bronchiolar Clara cells, plays an important protective role in the respiratory tract against oxidative stress and inflammation. The purpose of the study was to investigate the role of elemental carbon ultrafine particles (EC-UFP)-induced oxidative stress on Clara cells and CC16 in a mouse model of allergic lung inflammation.

Methods: Ovalbumin (OVA)-sensitized mice were exposed to EC-UFP $\left(507 \mu \mathrm{g} / \mathrm{m}^{3}\right.$ for $24 \mathrm{~h}$ ) or filtered air immediately prior to allergen challenge and systemically treated with $\mathrm{N}$-acetylcysteine (NAC) or vehicle prior and during EC-UFP inhalation. CC16 was measured up to one week after allergen challenge in bronchoalveolar lavage fluid (BALF) and in serum. The relative expression of CC16 and TNF-a mRNA were measured in lung homogenates. A morphometrical analysis of mucus hypersecretion and electron microscopy served to investigate goblet cell metaplasia and Clara cell morphological alterations.
\end{abstract}

Results: In non sensitized mice EC-UFP inhalation caused alterations in CC16 concentration, both at protein and mRNA level, and induced Clara cell hyperplasia. In sensitized mice, inhalation of EC-UFP prior to OVA challenge caused most significant alterations of BALF and serum CC16 concentration, BALF total protein and TNF-a relative expression compared to relevant controls; their Clara cells displayed the strongest morphological alterations and strongest goblet cell metaplasia occurred in the small airways. NAC strongly reduced both functional and morphological alterations of Clara cells.

Conclusion: Our findings demonstrate that oxidative stress plays an important role in EC-UFP-induced augmentation of functional and morphological alterations of Clara cells in allergic lung inflammation.

\section{Background}

There is rapidly increasing epidemiological evidence associating respiratory health effects and exposures to ultrafine particles (UFP) in a susceptible population, such as elderly, young children, and people with pre-existing respiratory conditions [1]. For adult asthmatics, ambient levels of UFP (aerodynamic diameter $<0.1 \mu \mathrm{m}$ ) were found to have a higher specific toxicological role compared to larger particles [2]. UFP, due to their large sur-

\footnotetext{
* Correspondence: franci@helmholtz-muenchen.de

1 Division of Environmental Dermatology and Allergy, Helmholtz Zentrum/ Technische Universität München, Helmholtz Zentrum München, German Research Center for Environmental Health $(\mathrm{GmbH})$, Ingolstaedter Landstrasse 1, 85764 Neuherberg, Germany, ZAUM Center for Allergy and Environment, Biedersteinerstrasse 29, 80802 Munich, Germany

Full list of author information is available at the end of the article
}

face area, have enhanced capabilities to produce reactive oxygen species [3].

Clara cells are non-ciliated secretory epithelial cells lining the pulmonary airways, distinct from mucous and serous secretory cells in morphology and secretory products [4]. In rodents Clara cells represent the most frequent secretory cell population of proximal and distal airways [5]. Their function is mainly to protect the respiratory tract. Clara cells act as stem cells in the repair of bronchial and bronchiolar epithelium, have a high xenobiotic transformation capacity and secrete several proteins with important biological activities [6]. The main secretory molecule is a $16 \mathrm{kD}$ protein (termed CC16, CC10, or CCSP), which is found in the electron dense, ovoid secretory granules, within the endoplasmic reticulum of Clara cells [7] and in the lining fluid throughout 
the conducting airways [8]. The immunomodulatory activity of CC16 has been well documented $[9,10]$. CC16 can inhibit phospholipase A2 activity [11], while inflammatory cytokines like TNF- $\alpha$ can modulate $\mathrm{CC} 16$ production [12]. In humans CC16 has been successfully used as a marker of alveolo-capillary barrier permeability [1315]. Investigations of Clara cells response to inhaled particulates reflect the toxic effects of these particles to the respiratory tract [16]. Previous studies have reported alterations of $\mathrm{CC} 16$ concentrations in BALF and serum following exposure to cigarette smoke, ozone or DEP [1719]. CC16 knockout mice showed aggravated early proinflammatory response to oxidant challenge [20,21], indicating a protective role of $\mathrm{CC} 16$ against acute oxidative stress.

Allergic asthma is characterized by airway hyperresponsiveness, airway inflammation, increased mucus production and lower antioxidant defenses [22]. The role of Clara cells and their secretory products in asthma is still controversial. Clara cells seem to exert protective effects against the development of the disease [23-26]; conversely, they are involved in allergen-induced mucus production $[27,28]$. We recently showed that particleinduced oxidative stress plays an important role in UFPinduced exacerbation of allergic airway inflammation [29].

The aim of the present study was to investigate the role of particle-induced oxidative stress on functional and morphological alterations of Clara cells in a mouse model of lung allergic inflammation. We measured serum and BALF CC16 concentration, CC16 relative expression in the lung in parallel to its activator TNF- $\alpha$, and evaluated morphological alterations of Clara cells and goblet cell hyperplasia with and without the addition of the antioxidant NAC.

\section{Materials and methods Animals and materials}

Five to seven-week-old Balb/c mice (Charles River, Sulzfeld, Germany) were housed in individually ventilated cages (VentiRack ${ }^{\mathrm{m}}$, cage type CU-31, BioZone, Ramsgate, Kent, UK) and received a standard pellet diet and water ad libitum. The study was conducted under federal guidelines for the use and care of laboratory animals and was approved by the Government of the District of Upper Bavaria. All chemicals were purchased from Sigma-Aldrich Chemie, Deisenhofen, Germany, unless otherwise specified.

\section{Allergen sensitization/challenge protocol}

Mice were sensitized by repetitive intraperitoneal injections of $1 \mu \mathrm{g}$ OVA (grade VI; Sigma Aldrich Chemie)/ Alum (2.5 mg; Pierce Chemical Co, Rockfort, IL, USA) in phosphate buffered saline (PBS) on days $0,7,14,28,42$,
56. Blood samples were taken before and after sensitization. OVA-specific IgE and IgG1 were measured in plasma samples by ELISA as described previously [30]. OVA/alum sensitized mice (day 63), compared to nonsensitized controls, were characterized by high titers of OVA-specific IgE $(24.2 \pm 1.8 \mathrm{vs} 0.1 \pm 0.01 \mu \mathrm{g} / \mathrm{ml})$ and OVA-specific IgG1 $(1392.6 \pm 182.6 \mathrm{vs}<0.1 \mu \mathrm{g} / \mathrm{ml})$. On day 70 the mice were aerosol-challenged for $20 \mathrm{~min}$ with 1\%-LPS-depleted [30] OVA in PBS or with PBS alone delivered by Pari-Boy nebulizer (Pari GmbH, Starnberg, Germany).

\section{EC-UFP production, characterization and exposure}

EC-UFP were generated by electric spark discharge (model GFG1000, Palas GmbH, Karlsruhe, Germany) using agglomerated carbon particles as previously described $[29,30]$. EC-UFP average size distributions were characterized by a count median diameter of 51.7 $\mathrm{nm}$ (geometric standard deviation $=1.54$ ) and an average mass median diameter of $84.7 \mathrm{~nm}$. Spark generated ECUFP are considered to be structurally similar and form aggregates similarly to the primary particles of modern diesel emissions [31], but with extremely low condensed organic matter. Organic carbon content of EC-UFP was estimated less than $5 \%$ by evolved gas analysis and Fourier transform analysis [32]. Spark generated EC-UFP are then considered to be relatively inert particles compared to diesel exhaust or concentrated atmospheric particles. We chose them for the inhalation exposure because of their defined chemical composition and stable physical characteristics during the $24 \mathrm{~h}$ exposure experiment.

Details of animal exposures were described previously [29]. All EC-UFP exposures used for this study were performed for $24 \mathrm{~h}$ with a mass concentration of $507 \mu \mathrm{g} / \mathrm{m}^{3}$, which corresponds to an average particle number concentration of $9.3 \times 10^{6} / \mathrm{cm}^{3}$.

\section{Experimental design}

A schematic representation of the study protocol is shown in Fig. 1.

In order to evaluate the effect of EC-UFP-induced oxidative stress on functional and morphological alterations of Clara cells, sensitized (S) and subsequently challenged mice (OVA) were exposed to EC-UFP with (S/NAC/UFP/ OVA) and without NAC treatment (S/UFP/OVA). NAC was administered with two intraperitoneal injections $(250 \mathrm{mg} / \mathrm{kg}$ body weight in PBS, $200 \mu \mathrm{l}), 1 \times$ shortly before and $1 \times$ close to mid-EC-UFP exposure. OVA sensitized and subsequently challenged mice exposed to filtered air (S/OVA) and non sensitized (NS) or sensitized mice exposed to EC-UFP (NS/UFP, S/UFP) with and without NAC treatment served as controls. In addition, untreated animals served as baseline controls $(\mathrm{n}=8)$. Before bronchoalveolar lavage (BAL), blood samples were taken from 


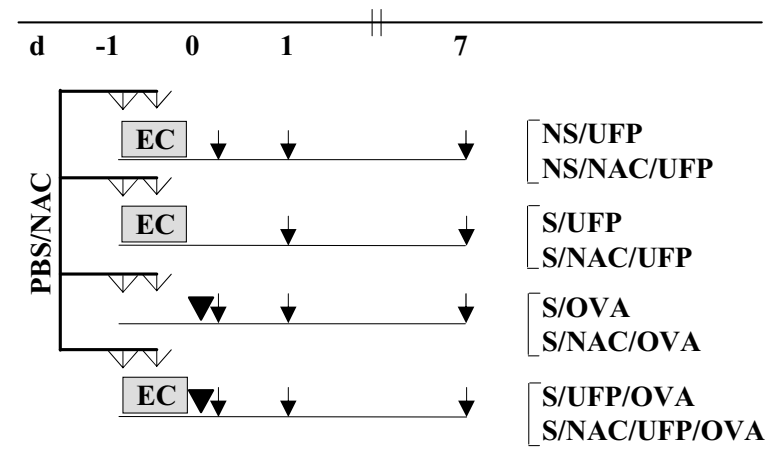

$\downarrow$ Sacrifice $\quad \nabla$ OVA challenge EC UFP exposure

Figure 1 Experimental groups (left) and designation (right). EC, 24 h exposure to elemental carbon UFP $\left(507 \mu \mathrm{g} / \mathrm{m}^{3}\right)$; open arrows, $2 \times$ intraperitoneal injection with $\mathrm{N}$-acetylcysteine; black triangle, OVA aerosol challenge; , sacrifice, BAL, histology and electron microscopy. S, sensitized; NS, non sensitized; OVA, challenged with aerosolized OVA; UFP, exposed to EC-UFP.

retro orbital plexus and centrifuged. Serum aliquots were stored at $-80^{\circ} \mathrm{C}$. BAL was performed at 0,1 , or 7 days after OVA challenge, or after termination of EC-UFP exposure ( $\mathrm{n}=4 /$ time point). After centrifugation, BALF was stored at $-80^{\circ} \mathrm{C}$ for subsequent analysis. Lungs were stored in formalin for histology/snap frozen in liquid nitrogen and stored at $-80^{\circ} \mathrm{C}$ for isolation of RNA. Airway hyperresponsiveness was evaluated by body plethysmography in untreated animals, or $24 \mathrm{~h}$ after OVA challenge in $\mathrm{S} /$ OVA, S/UFP/OVA and S/NAC/UFP/OVA $(n=5-7)$.

\section{Bronchoalveolar lavage (BAL) analysis}

Airways were lavaged five times with $0.8 \mathrm{ml}$ PBS. Aliquots of cell-free BAL fluid were assayed in duplicate for total protein (Coomassie Protein Assay, Pierce Chemical Co.) and for IL-5, IFN- $\gamma$ and IL-13 by two site ELISAs using antibodies from BD Biosciences (IL-5 and IFN- $\gamma$, Heidelberg, Germany) and BioSource (IL-13, Camarillo, CA, USA) as suggested by the manufacturer. Viability and yield of BAL cells was quantified via trypan blue exclusion in a hemocytometer. Differential BAL cell count $(400$ cells/sample) was performed on cytospins (600 rpm for $10 \mathrm{~min}$ ) fixed and stained with Diff-Quick (Dade Behring, Marburg, Germany).

\section{Determination of $\mathrm{CC} 16$ in BALF and serum}

Cell-free BALF and serum aliquots were assayed in duplicate for $\mathrm{CC} 16$ by an automated latex immunoassay using a polyclonal rabbit antibody raised against rat $\mathrm{CC} 16$ and applicable to both rat and mouse CC16 analysis [33].

\section{RNA extraction and real time RT-PCR}

Real-time RT-PCR analysis was performed in the lungs retrieved 1 day after EC-UFP exposure/allergen challenge. After homogenization, total RNA was isolated from total lung tissue using the RNeasy Mini kit (Qiagen $\mathrm{GmbH}$, Hilden, Germany) as per supplier's instructions. First strand cDNA synthesis was performed using the iScript cDNA synthesis kit (BioRad Laboratories GmbH, München, Germany). Quantitative PCR was performed using TaqMan Gene Expression Assays (CC16: Mm01230908_m1; TNF- $\alpha$ : Mm00443258_m1; 18S: Hs99999901_s1) and TaqMan Universal PCR Master Mix in an ABIprism7000 Sequence Detection System (Applied Biosystems, Darmstadt, Germany). The mRNA expression levels were normalised to the according expression levels of the housekeeping gene $18 \mathrm{~S}$ and the mean expression levels of the untreated group using the $\Delta \Delta \mathrm{C}_{\mathrm{T}}$ method.

\section{Histological evaluation and morphometrical analysis}

After BAL the lungs were removed and fixed in 10\% buffered formalin. The left lobe was used for histopathology. After paraffin embedding, $3.5 \mu \mathrm{m}$ sections were stained with hematoxylin-eosin (H\&E) and periodic acid Schiff (PAS). In order to evaluate goblet cell metaplasia and mucus hypersecretion, we performed a morphometrical analysis of volume density of PAS positive material (double square lattice test system E80 [34] and Optimas software package, Washington, USA) in cross sections of small (circumference $\leq 800 \mu \mathrm{m}$ ), and large (circumference $>800 \mu \mathrm{m}$ ) airways of the following groups: NS/UFP, S/ OVA, S/UFP/OVA and S/NAC/UFP/OVA. The data are expressed as percentage of PAS positive material/total epithelial cells.

\section{Transmission (TEM) and scanning (SEM) electron microscopy}

For electron microscopy, lungs were fixed by intratracheal perfusion with $2.5 \%$ glutaraldehyde in $0.1 \mathrm{M}$ cacodylate buffer ( $\mathrm{pH}$ 7.4), ( $\mathrm{n}=2$ /time point/group). For TEM peripheral and central sections of the right lung were minced, for SEM the left lung was cut longitudinally; all lung samples were fixed for further 4-7 days in glutaraldehyde and postfixed in 1\% osmiumtetroxide in cacodylate buffer for $1 \mathrm{~h}$ at $4^{\circ} \mathrm{C}$. For TEM the samples were embedded in EMbed 812 (Science Services, München, Germany). Semithin sections $(500 \mathrm{~nm})$ stained with Richardson solution (methylenblue, azur II) were used for selecting the portion suitable for electron microscopy. Then, ultrathin sections (silver coloured) were cut, mounted on formvar-coated 75-mesh nickel grids, double-stained with uranyl acetate and lead citrate and observed in a transmission electron microscope (JEOL 
1210, Tokyo, Japan) at $80 \mathrm{kV}$. Photographs were taken using Kodak 4489 films.

For SEM, the specimens were rinsed twice in cacodylate buffer, dehydrated in an ascending series of ethanols and critical point dried. The lungs were then mounted on plates using Leit-Tabs (Plano, Wetzlar, Germany), sputter-coated with $10 \mathrm{~nm}$ gold and examined in a scanning electron microscope (JEOL 6300, Tokyo, Japan) working at $15 \mathrm{kV}$. Photographs were taken using a digitalized image processing system.

\section{Lung function tests}

Lung function tests were performed $24 \mathrm{~h}$ after allergen challenge in unrestrained animals using whole body plethysmography (Buxco Electronics, Sharon, Connecticut, USA). For whole body plethysmography, the 'enhanced pause' (PenH) determined before and after methacholine exposure was applied as an index of airway hyperresponsiveness (AHR), as previously described $[29,30]$. The doses of methacholine aerosol (M1-M5) delivered to the mice were the following: $10 \mathrm{mg} / \mathrm{ml}$ methacholine nebulized for 1, 2 and 4 minutes (M1-M3), followed by $40 \mathrm{mg} / \mathrm{ml}$ methacholine for 2 and 4 minutes (M4-M5). A data recording interval of 3 min was introduced after each methacholine level. The mean of the PenH values determined in the $2^{\text {nd }}$ and $3^{\text {rd }}$ min was used for quantifying AHR.

\section{Statistical analysis}

Data were expressed as mean \pm SD. For statistical evaluation, one-way analysis of variance (ANOVA) with posthoc Scheffé Test (applied for BAL cells and BALF total protein, cytokines and morphometrical analysis) and Least Significant Difference-Test (LSD) (applied for CC16 analysis in BALF and serum, CC16 and TNF- $\alpha$ relative mRNA expression and airway hyperresponsiveness) comparisons were used (Statistica Stat Soft, 6.0). A pvalue $<0.05$ was considered to be significant.

\section{Results \\ NAC reduced EC-UFP-induced alterations in CC16 concentrations in BALF and serum}

The concentrations of CC16 in BALF and serum of untreated mice are shown in Fig. 2 by a dotted line. Non sensitized and sensitized mice exposed to EC-UFP for 24 $\mathrm{h}$ (NS/UFP, S/UFP) showed a significant decrease in CC16 in BALF at 1-day time point (Fig. 2a, upper panel). EC-UFP-induced decrease in BALF CC16 concentrations were abrogated by NAC treatment (NS/NAC/UFP; S/ NAC/UFP). One week after EC-UFP inhalation, BALF CC16 concentrations almost reached the control level. In sensitized mice, OVA challenge alone caused a transitional reduction in CC16 content in BALF at 1-day time point (S/OVA, Fig. 2b, upper panel). NAC minimally reduced OVA-induced CC16 alterations (S/NAC/OVA). Sensitized mice exposed to EC-UFP inhalation prior to allergen challenge showed an initial significant reduction in BALF CC16, followed by a significant increase in $\mathrm{CC} 16$ BALF content at the 7-day time point compared to untreated animals, NS/UFP, S/UFP and to S/OVA (S/ UFP/OVA, Fig. 2b, upper panel). NAC treatment significantly reduced this increase (S/NAC/UFP/OVA).

In contrast to BALF CC16 concentrations, serum CC16 concentrations increased significantly following exposure to EC-UFP in both non sensitized and sensitized mice (Fig. 2a, bottom panel). Increased CC16 concentrations in serum were detectable also one week after EC-UFP inhalation. NAC reduced serum $\mathrm{CC} 16$ concentrations in sensitized mice exposed to EC-UFP at the 7 days time point (Fig. 2a, bottom panel). In S/OVA serum CC16 concentrations were increased compared to untreated animals at all time points of evaluation (S/OVA, Fig. 2b, bottom panel) and NAC treatment had no effect on serum CC16 concentration (S/NAC/OVA). In sensitized animals, EC-UFP inhalation followed by allergen challenge further increased serum CC16 concentration (S/ UFP/OVA, Fig. 2b, bottom panel). NAC treatment significantly reduced the EC-UFP-induced increased serum CC16 concentrations (S/NAC/UFP/OVA).

\section{NAC reduced EC-UFP-induced alterations in BALF total protein concentration, cytokines and airway inflammation}

The concentration of BALF total protein in untreated mice is shown in Fig. 3 by a dotted line. In sensitized mice, OVA challenge alone caused an increase in BALF total protein concentration compared to control, which was significantly reduced by NAC treatment (Fig. 3b). A further increase of BALF total protein was detected in sensitized mice exposed to EC-UFP inhalation prior to OVA challenge (S/UFP/OVA) at the 7 days time point (Fig. 3b). NAC significantly reduced BALF total protein concentrations (S/NAC/UFP/OVA) at the 7 days time point. No induction of protein levels were observed in any of the non-challenged groups (NS/UFP, S/UFP, with and without NAC treatment, Fig. 3a).

In sensitized mice, EC-UFP inhalation prior to OVA challenge (S/UFP/OVA) caused a significant increase of BAL inflammatory infiltrate and BALF cytokines IL-5 and IL-13 7 days after OVA challenge, compared with sensitized and challenged mice exposed to filtered air (S/ OVA); NAC treatment significantly reduced EC-UFPinduced augmentation of lung allergic inflammation (S/ NAC/UFP/OVA), (See additional file 1: functional characterization of the mouse model). NAC non-significantly reduced airway inflammation in S/OVA mice (S/NAC/ OVA, see additional file 1: functional characterization of the mouse model). No significant alterations in the IFN- $\gamma$ concentration were observed in any of the groups (data 


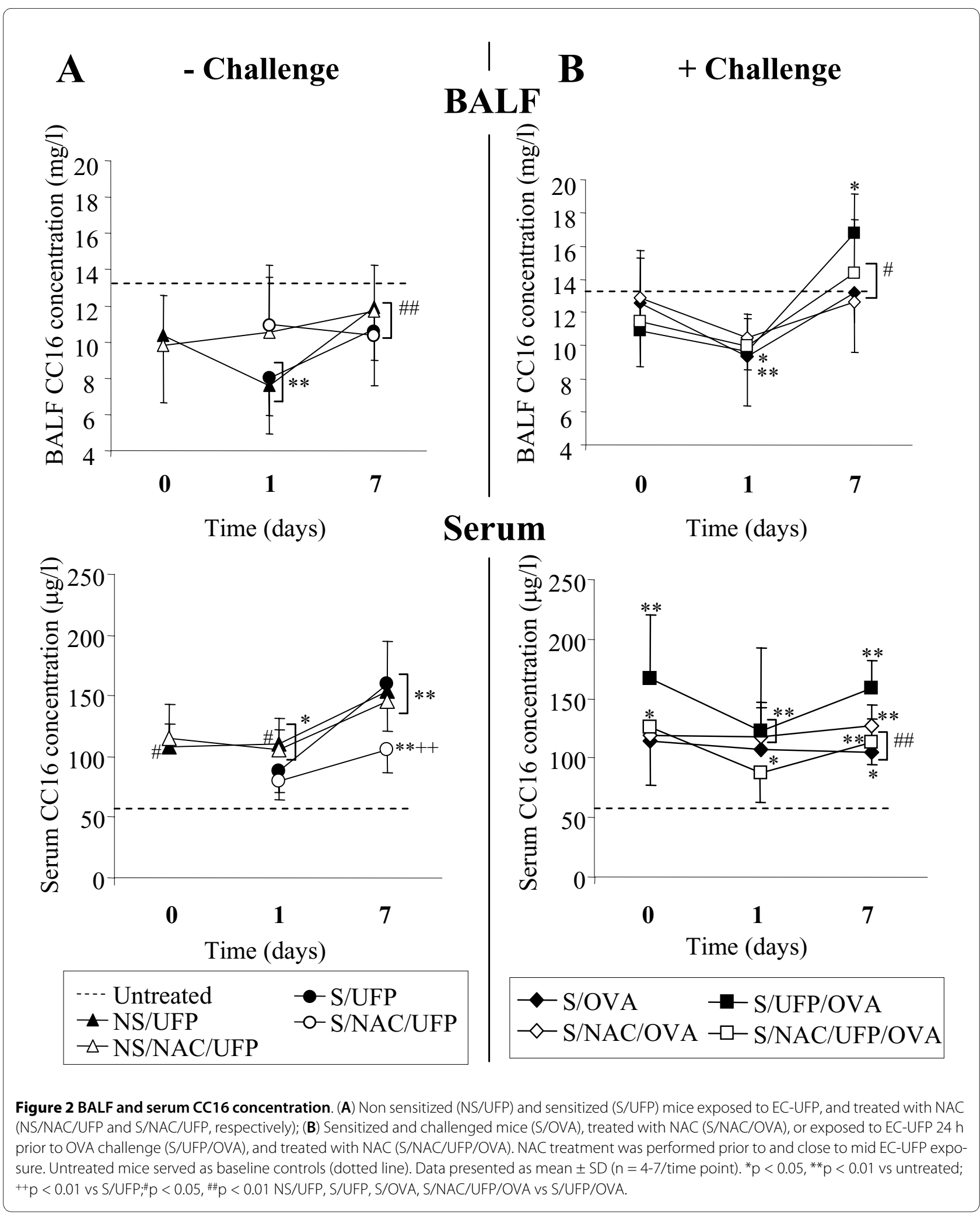



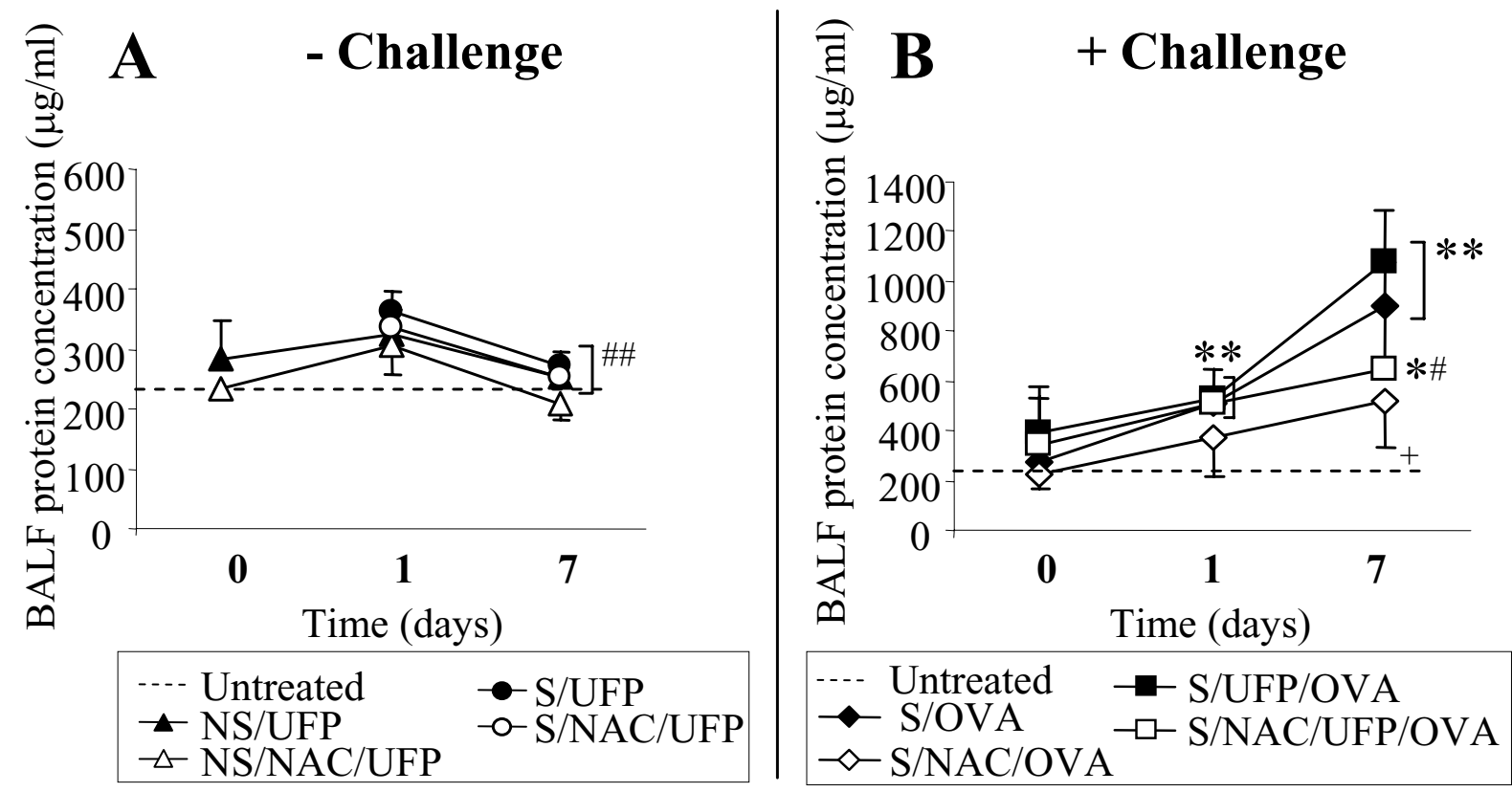

Figure 3 BALF total protein concentration. (A) Non sensitized (NS/UFP) and sensitized (S/UFP) mice exposed to EC-UFP, and treated with NAC (NS/ NAC/UFP and S/NAC/UFP, respectively); (B) Sensitized and challenged mice (S/OVA), treated with NAC (S/NAC/OVA), or exposed to EC-UFP $24 \mathrm{~h}$ prior to OVA challenge (S/UFP/OVA), and treated with NAC (S/NAC/UFP/OVA). NAC treatment was performed prior to and close to mid EC-UFP exposure. Untreated mice served as baseline controls (dotted line). Data presented as mean $\pm S D\left(n=4-8 /\right.$ time point). ${ }^{*} p<0.05,{ }^{*} p<0.01 \mathrm{vs} \mathrm{untreated;}{ }^{+} p<$ 0.05 vs S/OVA; $\# p<0.05, \# p<0.01$ NS/UFP, S/UFP, S/OVA, S/NAC/UFP/OVA vs S/UFP/OVA.

not shown). Non sensitized mice exposed to EC-UFP did not develop an inflammatory infiltrate and showed no cytokine release (NS/UFP, see additional file 1: functional characterization of the mouse model).

\section{At the mRNA level, NAC failed to reduce EC-UFP-induced alterations of CC16, but reduced EC-UFP-induced TNF-a relative expression}

CC16 and TNF- $\alpha$ relative mRNA expression was evaluated at 1-day time point in lung homogenates. The relative mRNA expression of CC16 and TNF- $\alpha$ in untreated mice is shown in Fig. 4 by a dotted line. In sensitized and non sensitized mice EC-UFP exposure alone induced an increase in CC16 and TNF- $\alpha$ relative mRNA expression compared to untreated mice (Fig. 4a, upper and bottom panel respectively). In sensitized animals allergen challenge alone had no significant effects on relative $\mathrm{CC} 16$ mRNA expression, but significantly increased TNF- $\alpha$ expression (S/OVA, Fig. 4b, upper and bottom panel, respectively). In sensitized animals, EC-UFP exposure prior to allergen challenge increased CC16 mRNA expression similarly to NS/UFP and S/UFP (S/UFP/OVA, Fig. 4b, upper panel), whereas it significantly increased TNF- $\alpha$ expression compared to all other groups (S/UFP/ OVA, Fig. 4b, bottom panel). NAC moderately reduced
CC16 and TNF- $\alpha$ mRNA expression in non challenged animals (NS/NAC/UFP, Fig. 4a, striped bars). In sensitized and challenged animals NAC failed to reduce ECUFP-induced increase in CC16 expression, but strongly reduced EC-UFP-induced increase in TNF- $\alpha$ mRNA expression (S/NAC/UFP/OVA, Fig. 4b, upper and bottom panel, respectively, striped bars).

\section{NAC strongly reduced EC-UFP-induced mucus hypersecretion in allergic animals}

In order to evaluate the degree of goblet cell metaplasia and mucus hypersecretion we performed a morphometrical analysis of PAS positive material in histological specimen retrieved 7 days after allergen challenge/ECUFP inhalation. NS/UFP showed no PAS positive material (Fig. 5a, b, c). In sensitized animals allergen challenge alone had a significant effect on goblet cell metaplasia and mucus hypersecretion (Fig. 5a, b, d). EC-UFP exposure prior to allergen challenge increased goblet cell metaplasia and mucus hypersecretion in the small airways, but not in the large airways (Fig. 5a, b, e). NAC treatment prior and during EC-UFP inhalation significantly decreased goblet cell metaplasia and mucus hypersecretion both in small and large bronchi (Fig. 5a, b, f). 


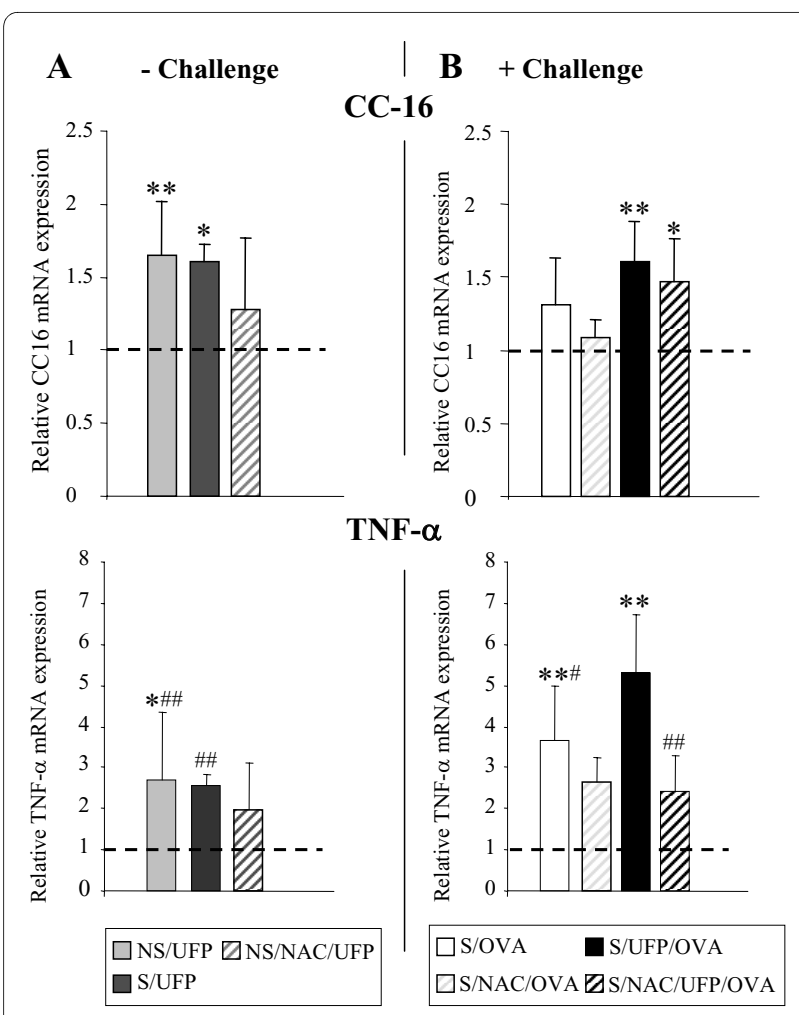

Figure $4 \mathrm{CC} 16$ and TNF-a relative mRNA expression in lung homogenates. (A) Non sensitized (NS/UFP) and sensitized (S/UFP) mice exposed to EC-UFP, and NS/UFP treated with NAC (NS/NAC/UFP); (B) sensitized and challenged mice (S/OVA), treated with NAC (S/NAC/ OVA), or exposed to EC-UFP $24 \mathrm{~h}$ prior to OVA challenge (S/UFP/OVA), and treated with NAC (S/NAC/UFP/OVA). NAC treatment was performed prior to and close to mid EC-UFP exposure. Untreated mice served as baseline controls (dotted line). The lungs were retrieved $24 \mathrm{~h}$ after EC-UFP/filtered air exposure. Data presented as mean \pm SD $(n=$ $3-6 /$ group). ${ }^{*} p<0.05,{ }^{* *} p<0.01$ vs untreated; ${ }^{*} p<0.05$, ${ }^{\#} p<0.01$ NS/ UFP, S/UFP, S/OVA, S/NAC/UFP/OVA vs S/UFP/OVA.

\section{NAC strongly reduced EC-UFP-induced morphological alterations in Clara Cells}

In the analysis of the samples performed by SEM and TEM, we focussed on the small airways (circumference $\leq$ $800 \mu \mathrm{m})$, one week time point. In untreated mice, Clara cells appeared as cuboidal cells with a central narrow projection into the airway lumen covered with short microvilli (Fig. 6, untreated). The upper third of the cell contained well organized arrays of smooth endoplasmatic reticulum. Two types of mitochondria could be observed; one small and elongated with cristae and the other large and usually round, with few or no cristae. Dense homogenous secretory granules (Fig. 6, untreated, arrows) bound by a single limiting membrane were located near the apex of the Clara cells most regularly immediate below the luminal membrane. Both merocrine and apocrine secretions were observed. Throughout the depth of the epithelium there were close connections between adjacent cells.
No goblet cells could be detected. At the SEM, Clara cells from untreated mice appeared often arranged in a pattern forming lines. They showed dome-shaped apical projections into the lumen with rough surfaces (Fig. 7, untreated).

Following EC-UFP exposure, no particles could be detected within Clara cells. EC-UFP inhalation alone induced alterations in the morphology of Clara cells. In TEM as well as in SEM the Clara cells of the bronchioli exhibited hyperplasia and proliferation, so that the ciliated cells seemed to be reduced in number and appeared to be constricted (Fig. 6, NS/UFP, arrow; Fig. 7, NS/UFP). Sensitized animals exposed to EC-UFP showed the formation of clusters of 3 or 4 Clara cells close together (Fig 7, S/UFP). NAC reduced to a great extent these morphological alterations: no clusters were found, and Clara cell surface displayed the typical dome-shaped apical projections as in untreated mice (Fig. 6 and 7, NS/NAC/UFP and $\mathrm{S} / \mathrm{NAC} / \mathrm{UFP})$.

In S/OVA mice, the bronchioli featured goblet cell metaplasia: the dense homogenous secretory granules of the Clara cells converted to mucus containing vesicles, some of them containing dark residues of the secret (Fig. 6, S/OVA). Signs of partial necrosis were also present. Primarily merocrine secretion of mucus was found. The vesicles in close proximity to the cell surface were bulging the plasma membrane. Due to this effect, at the SEM analysis the surface area of the transformed cells exhibited a vesicular pattern (Fig. 7, S/OVA).

NAC treatment reduced the ultrastructural modifications of the Clara cells of S/OVA mice (data not shown).

In sensitized animals, EC-UFP exposure prior to OVA challenge produced most profound ultrastructural damage and necrosis. Goblet cell metaplasia was more pronounced compared to S/OVA animals. In some areas no rudiments of the secretory granules could be detected and the abundant smooth endoplasmatic reticulum as well as the dimorphic mitochondria were entirely displaced by mucous vesicles. Widening of the intercellular spaces and detachment of the epithelium were frequently observed (Fig. 6, S/UFP/OVA, arrows). At the SEM analysis, a few highly hyperplastic Clara Cells were noted within goblet cells (Fig. 7, S/UFP/OVA, arrows).

NAC treatment extensively reduced the described morphological alterations. Over broad ranges of bronchioli Clara cells displayed normal features. Necrosis appeared to a striking less degree. Also at the SEM analysis, the surface of the Clara cells exhibited obvious less vesicular pattern (Fig. 6 and 7, S/NAC/UFP/OVA).

NAC reduced EC-UFP-induced airway hyperresponsiveness Airway hyperresponsiveness as measured by body plethysmography $24 \mathrm{~h}$ after OVA challenge showed significantly increased enhanced pause (PenH) following 

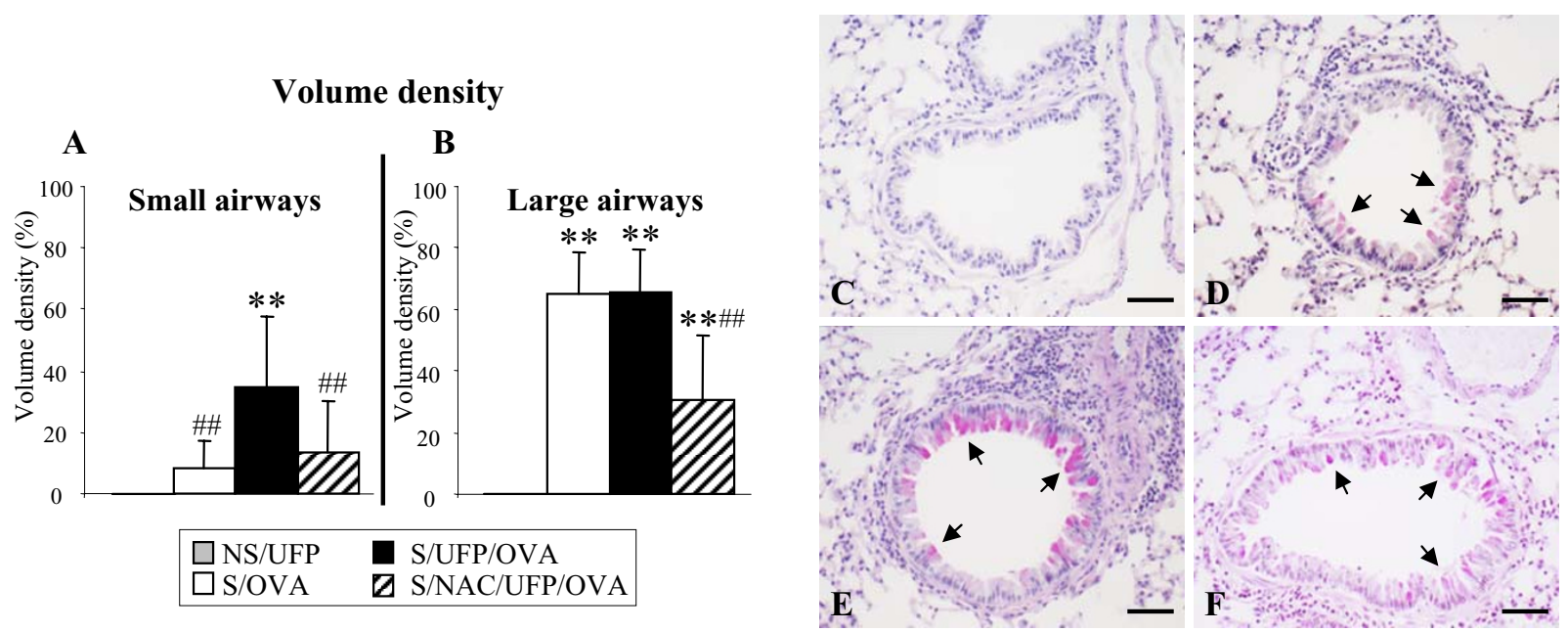

Figure 5 Morphometrical analysis of volume density of PAS positive material. NS/UFP, S/OVA, S/UFP/OVA and S/NAC/UFP/OVA lungs were retrieved 7 days after OVA challenge/EC-UFP inhalation and stained with PAS. (A) Small airways (circumference $\leq 800 \mu$ m); (B) Large airways (circumference $>800 \mu \mathrm{m}), n=6-12 /$ group. ${ }^{* *} p<0.01$ vs NS/UFP; \#\# $<0.01$ vs S/UFP/OVA. Representative samples of lungs stained with PAS showing small airways in: (C) Non sensitized mice exposed EC-UFP (NS/UFP); (D) Sensitized and challenged mice exposed to filtered air (S/OVA); (E) Sensitized mice exposed to EC-UFP $24 \mathrm{~h}$ prior to OVA challenge (S/UFP/OVA); (F) Sensitized mice exposed to EC-UFP $24 \mathrm{~h}$ prior to OVA challenge and treated with NAC (S/NAC/UFP/OVA). Arrows, mucus hypersecretion; scale bar, $50 \mu \mathrm{m}$.

increasing methacholine concentrations in OVA sensitized animals exposed to EC-UFP prior to OVA challenge (S/UFP/OVA) compared to untreated; a close to significant increase in $\mathrm{PenH}$ was shown in comparison with sensitized and challenged mice exposed to filtered air ( $\mathrm{S}$ / OVA). NAC reduced EC-UFP-dependent increase in airway hyperresponsiveness (See additional file 1: functional characterization of the mouse model).

\section{Discussion}

Epidemiological and experimental studies suggest that anthropogenic air pollutants, in particular fine and ultrafine particulate matter, are important cofactors in the development of pulmonary health disorders, including pulmonary allergic disorders [30,35-37]. Clara cells are nonciliated secretory epithelial cells lining the pulmonary airways, whose main function is to protect the respiratory system from excessive inflammatory reactions [8]. In this study we investigated functional and morphological alterations of Clara cells in a mouse model of UFP-induced exacerbation of allergic lung inflammation. Our results showed that sensitized and challenged mice exposed to EC-UFP prior to allergen challenge showed a transient decrease, followed by a late increase of CC16 in BALF accompanied by a strong increase of $\mathrm{CC} 16$ in serum. BALF total protein concentration was also most increased in this group, confirming that the exudative response caused by the increased airway permeability plays an important role. Similarly to our results, exposure to cigarette smoke provoked a lower CC16 recovery in
BALF and an increase in CC16 in serum [17]. In this study, the augmented albumin and total protein recovery in the BALF confirmed the increased particle-induced permeability of the lung/blood barrier. Interestingly, a recent study showed that cigarette smoke decreases transepithelial resistance resulting in a reduction of the epithelial barrier function [38]. We show similar effects using allergic mice, where lung injury caused by particle exposure and by allergic inflammation had synergistic effects. On the contrary, EC-UFP inhalation in non challenged non sensitized or sensitized mice had a transitional, though significant effect on CC16 concentrations in BALF, a significant effect on serum CC16 concentrations, but no effect on total protein recovery in BALF. Difference in particle characteristics, mainly the low toxicity of the relatively inert EC-UFP compared to cigarette smoke, characterized by a highly reactive gas phase and organics, might account for these discrepancies.

At the mRNA level, we show that EC-UFP alone stimulate CC16 expression in non sensitized and sensitized mice, independently from allergen challenge. This means that EC-UFP inhalation alone leads to increased intracellular storage of $\mathrm{CC} 16$ protein. While previous studies have reported that the mRNA level of CC16 in the respiratory tract is reduced after exposure to cigarette smoke, ozone, diesel exhaust and silicon carbide whiskers mineral fibers [17-19,39], the pulmonary response to intratracheal instillation of fine particles showed to increase CC16 mRNA expression [40]. This latter study is in line with our results. Altered expression of CC16 in the lung 


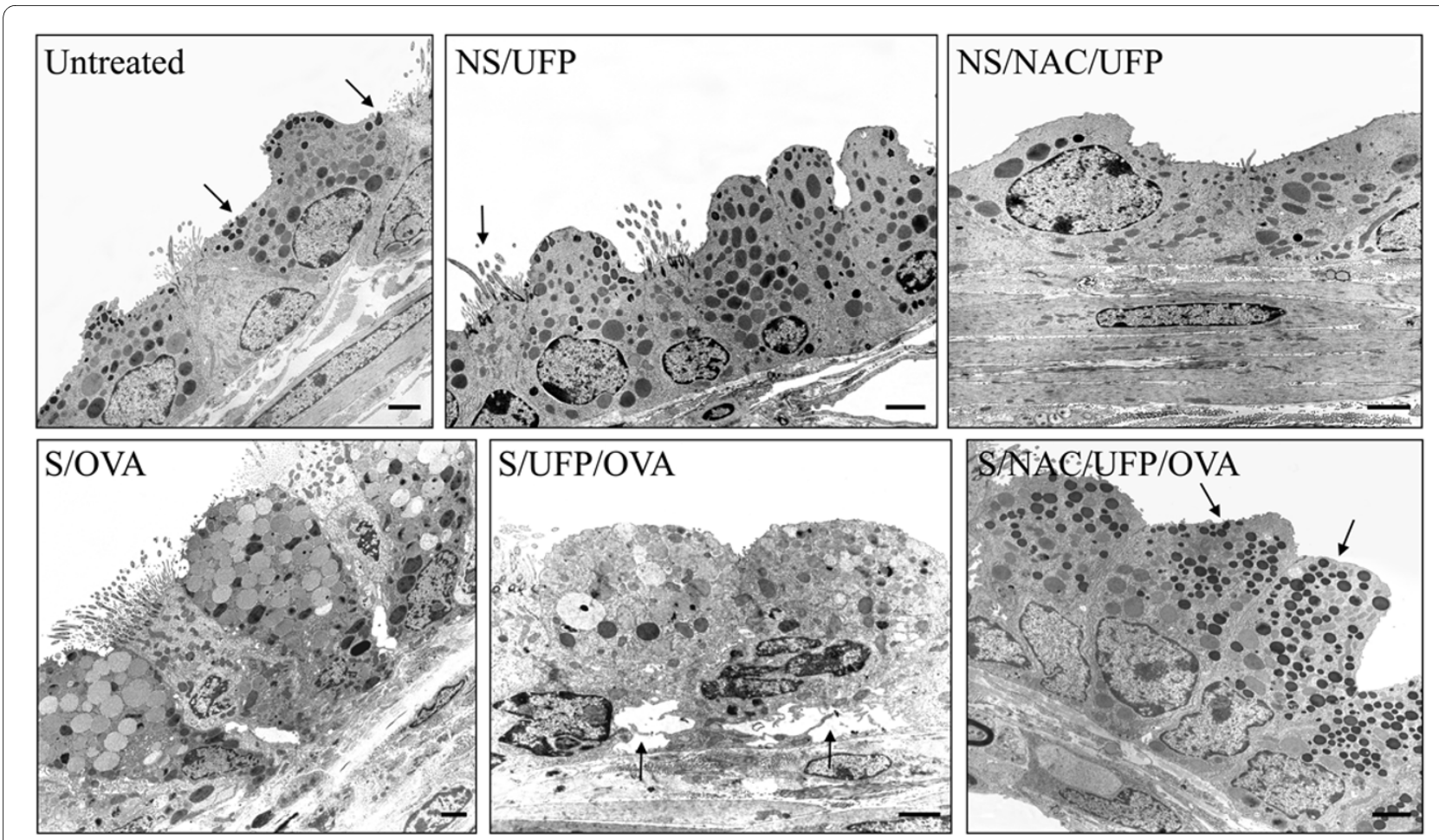

Figure 6 Transmission electron microscopy. Ciliated and non-ciliated (Clara) cells in the peripheral lung of normal control mice (Untreated). Merocrine secretions of electron-dense secretory granules (arrows) are recognized in the Clara cell exhibiting many mitochondria and developed smooth endoplasmic reticulum. Hyperplastic Clara cells in the lungs of non sensitized mice exposed to EC-UFP, (NS/UFP). The arrow points at a ciliated cell. NS/UFP treated with NAC (NS/NAC/UFP). OVA sensitized and challenged mice showing goblet cell metaplasia (S/OVA). Strong ultrastructural damage and detachment of metaplastic cells (arrows) is shown in the peripheral lungs of sensitized mice exposed to EC-UFP $24 \mathrm{~h}$ prior to OVA challenge (S/UFP/OVA). Clara cells of sensitized mice exposed to EC-UFP $24 \mathrm{~h}$ prior to OVA challenge and treated with NAC show preserved ultrastructure with secretory granules (arrows), (S/NAC/UFP/OVA). NAC treatment was performed prior to and close to mid EC-UFP exposure. Scale bar, $2 \mu \mathrm{m}$.

may depend on its key function. Most importantly, its anti-inflammatory activities include down-regulation of interferon- $\gamma$ and tumor necrosis factor-alpha synthesis and/or biological activity [9], inhibition of IL-1 $\beta$ and of phospholipase A2 in the synthesis of arachidonic acid metabolites [11]. CC16 may therefore contribute to the regulation of an inflammatory response in the lung [41]. In this study we measured also the expression of TNF- $\alpha$, an early-response multifunctional cytokine, produced mainly by monocytes and macrophages [42], which was shown to be synthesized in the lung following ultrafine particle exposure [43,44]. In addition to its pro-inflammatory characteristics, TNF- $\alpha$ was shown to stimulate human CC16 production [12]. In our model, EC-UFP inhalation alone increased TNF- $\alpha$ expression. Moreover, allergic inflammation and EC-UFP inhalation had synergistic effects on lung TNF- $\alpha$ expression.

Allergic asthma is a disease characterized by lower antioxidant defenses [22]. The role of Clara cells in asthma is still controversial. Studies in humans revealed decreased CC16 levels in BALF and serum of asthmatic patients compared to healthy individuals [23,25,45], suggesting that Clara cells may protect the lung against the develop- ment of the disease. Interestingly, the human gene for CC16 is localized within a chromosomal locus associated with regulation of inflammation and allergy [41] and an association has been found between a polymorphism in the $\mathrm{CC16}$ gene and an increased risk of developing asthma [24]. In addition, experimental studies showed a regulation of the Th2 response by CC16 [26]. On the other hand, there is increasing evidence that Clara cells are essential in allergen-induced mucus production in the airway epithelium and that these cells undergo metaplasia to goblet cells, being responsible for the formation of the mucus plugs which characterize the asthmatic phenotype $[27,28]$. Thus, our mouse model represents a susceptible population to the EC-UFP-induced oxidative stress, where Clara cells seem to play an important role.

Oxidative stress is said to occur in a tissue or an organ when the normal balance between oxidants and antioxidants shifts in favor of oxidants, from either an excess of oxidants and/or depletion of antioxidants. Recently we have shown increased marker of oxidative stress isoprostane following EC-UFP inhalation alone; sensitized mice exposed to EC-UFP before OVA challenge showed highest lung isoprostane concentrations, NF- $\mathrm{kB}$ activation 


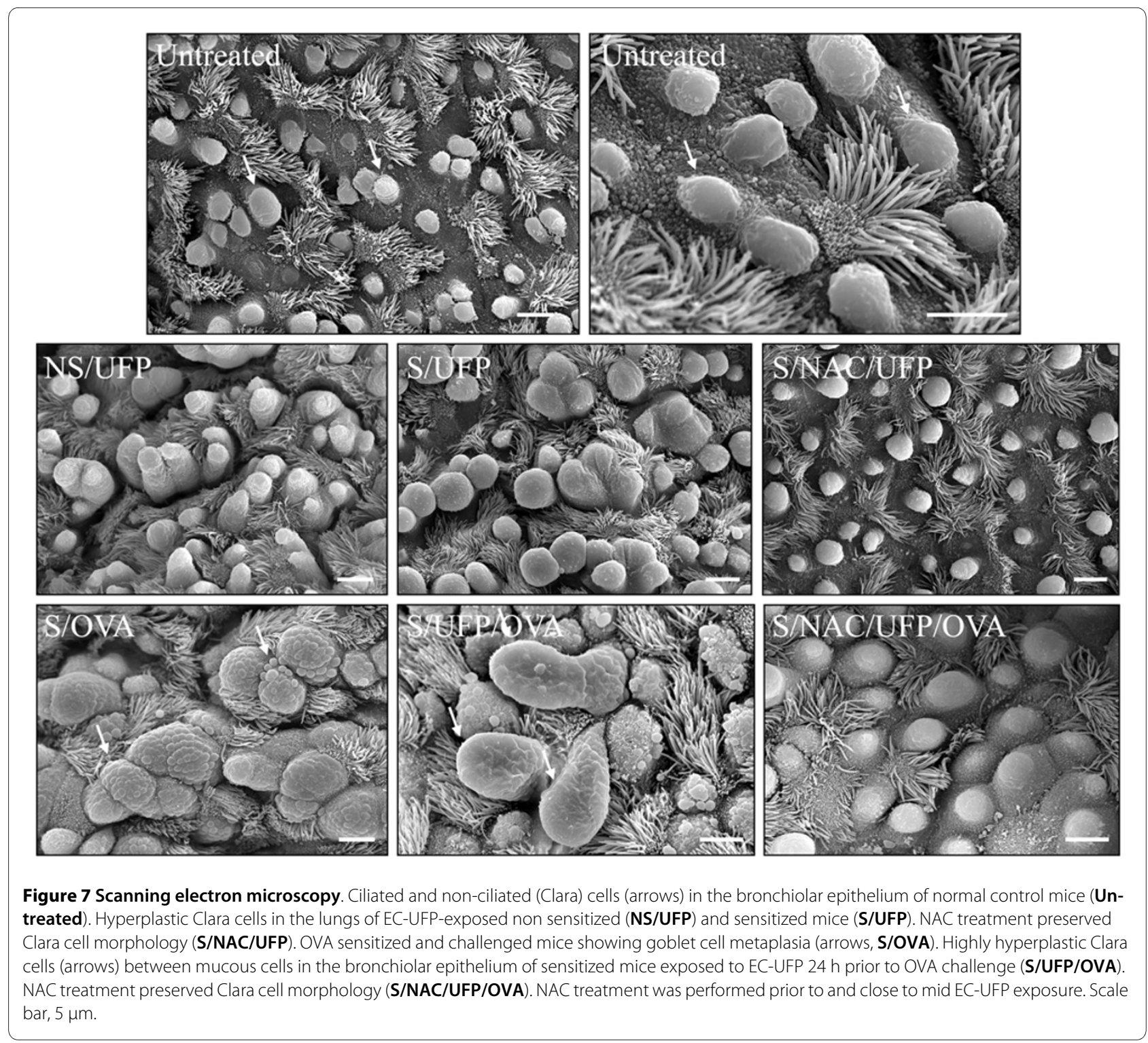

and airway hyperresponsiveness [29]. The role of CC16 in the protection against acute oxidative stress is well known. In fact, exposure to ozone was shown to increase serum CC16 concentrations [18] and CC16 -/- gene targeted mice showed increased susceptibility to hyperoxic injury and exaggerated inflammatory response compared to wild types $[20,21]$. In order to assess the role of oxidative stress in EC-UFP-induced alteration of Clara cells and $\mathrm{CC} 16$ concentration, we used NAC, a well-known thiol compound which acts directly as a free radical scavenger [46] and as a precursor of reduced glutathione (GSH) [47]. We chose NAC because it is relative innocuous, it has been widely used both in vitro and in vivo and it possess a short half life, therefore the antioxidant capabilities of NAC were limited only to the duration of ECUFP exposure [48]. Our results show that EC-UFP- induced alterations of CC16 concentrations were significantly reduced by NAC treatment, indicating the role of oxidative stress in the induction of $\mathrm{CC} 16$ release. Similarly, the antioxidant strategy reduced TNF- $\alpha$ mRNA expression in whole lung homogenate. On the contrary, NAC did not reduce significantly CC16 mRNA expression, implying that the regulation of $\mathrm{CC} 16$ by NAC may function at the post-transcriptional level. The effect of NAC on CC16 concentrations in serum was slightly more inconsistent than in BALF. This could be explained by the large gradient across the air/blood barrier, where a small variation in CC16 concentration in BALF can cause large variations in serum $\mathrm{CC} 16$ concentrations. Previous studies showed that NAC enhanced the production of CC16 in a mouse allergy model, a possible mechanism by which it may suppress airway inflammation [49]. In our model 
NAC had minor effects on lung CC16 concentrations of sensitized and challenged mice maybe because our model reproduces a mild allergic inflammation of the lung, as shown by the data on inflammatory cells, cytokines and airway hyperresponsiveness (See additional file 1: functional characterization of the mouse model). On the contrary, we show strong effects of NAC upon EC-UFP exposure.

Transmission and scanning electron microscopy served to investigate UFP-induced morphological alterations in Clara cells. EC-UFP are found in the ultrafine size range $(<100 \mathrm{~nm})$, which when inhaled, readily penetrate the lower respiratory tract [50]. However, we did not detect particles within Clara cells as we recently observed in other types of epithelial cells [29]. Thus, the morphological and functional alterations of Clara cells which we observed is most likely a consequence of particle indirect effects, such as alterations of inflammatory mediators in the lung lining fluid. Ultrastructural alterations of Clara cells were also shown following exposures to air pollutants such as ozone and tobacco smoke [21,51]. Acute injury to Clara cells induced by ozone exposure caused hyperplasia and loss of secretory granules [52]. Studies on CC16 /- mice showed that CC16 is required for the appearance of Clara cells secretory granules [53]. These studies suggest an important role for Clara cells and oxidant-induced secretion of $\mathrm{CC} 16$ as an immediate protective response to oxidative injury. Surprisingly, we showed hyperplasia of Clara cells (but no goblet cell metaplasia) following inhalation of relatively inert particles, such as EC-UFP. Sensitized and challenged mice exposed to filtered air were characterized by increased numbers of mucous cells derived by Clara cell metaplasia, as previously described [28]. In the morphometrical analysis of PAS positive material we showed that this phenomenon was significant only in the large airways. Interestingly, sensitized and challenged mice exposed to EC-UFP prior to challenge showed increased goblet cell metaplasia induced by EC-UFP exposure only in the small airways, in contrast to large airways. One explanation could be based on predominant ultrafine particle deposition in smaller compared to larger airways due to the velocity profiles generated in the airways by high frequency breathing in rodents and the increased residence time of particles in small structures favouring deposition by diffusional displacement [54,55]. Electron miscroscopy shows most dramatic alterations of Clara cell ultrastructure in this group, characterized by extreme hyperplasia, metaplasia with complete loss of secretory granules and necrosis. We show that oxidative stress plays an important role, since NAC treatment is able to limit goblet cell metaplasia and protect Clara cell ultrastructure.

\section{Conclusion}

Our study demonstrates the role of oxidative stress on Clara cell function and morphology in a mouse model of allergic inflammation of the lung. In healthy animals, Clara cells showed to contribute to the local needs upon cell damage caused by EC-UFP-induced oxidative stress. In allergic animals, the combination of goblet cell metaplasia, with associated mucus hypersecretion, and reduced host defence seems a disastrous pathophysiological combination, where the invoked compensatory mechanisms seem to be insufficient. For asthmatics, particle exposure would then exacerbate the already existing difficulty to counteract reactive oxygen species. Our data support the concept that allergic individuals are more susceptible to the adverse health effects of EC-UFP.

\section{List of Abbreviations}

CC16: Clara cell protein; EC-UFP: elemental carbon ultrafine particles; UFP: ultrafine particles; OVA: ovalbumin; NAC: N-acetylcysteine; BALF: bronchoalveolar lavage fluid; TNF- $\alpha$ : tumor necrosis factor alpha; DEP: diesel exhaust particles; PBS: phosphate buffered saline; ELISA: enzyme-linked immunosorbent assay; BAL: bronchoalveolar lavage; RT-PCR: reverse transcription-polymerase chain reaction; PAS: periodic acid Schiff; TEM: transmission electron microscopy; SEM: scanning electron microscopy.

\section{Additional material}

Additional file 1 Functional characterization of the mouse model.

Competing interests

The authors declare that they have no competing interests.

\section{Authors' contributions}

$F A$ and $\mathrm{HB}$ conceived the overall research idea, made substantial contributions to design, acquisition, analysis and interpretation of data. FA carried out all procedures for animal experiments and wrote the manuscript. IW contributed substantially to the study by performing all electron microscopy. EvM and AB performed and analysed CC16 assessment. ST performed the morphometrical analysis of the histological samples. HS performed lung function tests. EK supervised particles exposures and CB and MM supervised the gene expression analysis by real-time PCR. All authors read and approved the final manuscript.

\section{Acknowledgements}

We wish to thank Christine Weil, Martin Skerhut, Cordula Ebner von Eschenbach, Bettina Maar, Claudia Zeller and Bernd Lentner for excellent technical assistance. This project was partially funded by CK-CARE A.

\section{Author Details}

1Division of Environmental Dermatology and Allergy, Helmholtz Zentrum/ Technische Universität München, Helmholtz Zentrum München, German Research Center for Environmental Health $(\mathrm{GmbH})$, Ingolstaedter Landstrasse 1, 85764 Neuherberg, Germany, ZAUM Center for Allergy and Environment, Biedersteinerstrasse 29, 80802 Munich, Germany, 2Focus Network

Nanoparticles and Health (NanoHealth), Helmholtz Zentrum München, 
German Research Center for Environmental Health (GmbH), Ingolstaedter Landstrasse 1, 85764 Neuherberg, Germany, ${ }^{3}$ Laboratory of Toxicology and Applied Pharmacology, Faculty of Medicine, Catholic University of Louvain, 53.02 Avenue E. Mounier, B-1200 Brussels, Belgium, ${ }^{4}$ Institute of Lung Biology and Disease, Helmholtz Zentrum München, German Research Center for Environmental Health (GmbH), Ingolstaedter Landstrasse 1, 85764 Neuherberg, Germany and Institute of Ecological Chemistry, Helmholtz Zentrum München, German Research Center for Environmental Health $(\mathrm{GmbH})$, Ingolstaedter Landstrasse 1,85764 Neuherberg, Germany

Received: 26 November 2009 Accepted: 26 April 2010

Published: 26 April 2010

\section{References}

1. Pope CA: Epidemiology of fine particulate air pollution and human health: biologic mechanisms and who's at risk? Environ Health Perspect 2000, 108(Suppl 4):713-23.

2. Peters A, Wichmann HE, Tuch T, Heinrich J, Heyder J: Respiratory effects are associated with the number of ultrafine particles. Am J Respir Crit Care Med 1997, 155(4):1376-83.

3. Li N, Sioutas C, Cho A, Schmitz D, Misra C, Sempf J, Wang M, Oberley T, Froines J, Nel A: Ultrafine particulate pollutants induce oxidative stress and mitochondrial damage. Environ Health Perspect 2003, 111(4):455-60.

4. Smith MN, Greenberg SD, Spjut HJ: The Clara cell: a comparative ultrastructural study in mammals. Am J Anat 1979, 155(1):15-30.

5. Pack RJ, Al-Ugaily LH, Morris G: The cells of the tracheobronchial epithelium of the mouse: a quantitative light and electron microscope study. J Anat 1981, 132(Pt 1):71-84.

6. Massaro GD, Singh G, Mason R, Plopper CG, Malkinson AM, Gail DB: Biology of the Clara cell. Am J Physiol 1994, 266(1 Pt 1):L101-6.

7. Bedetti CD, Singh J, Singh G, Katyal SL, Wong-Chong ML: Ultrastructural localization of rat Clara cell $10 \mathrm{KD}$ secretory protein by the immunogold technique using polyclonal and monoclonal antibodies. $J$ Histochem Cytochem 1987, 35(7):789-94.

8. Singh G, Katyal SL: Clara cells and Clara cell 10 kD protein (CC10). Am Respir Cell Mol Biol 1997, 17(2):141-3.

9. Dierynck I, Bernard A, Roels H, De Ley M: The human Clara cell protein: biochemical and biological characterisation of a natural immunosuppressor. Mult Scler 1996, 1(6):385-7.

10. Hayward A: Who's to blame for asthma? Lancet 1995, 346(8985):1243.

11. Levin SW, Butler JD, Schumacher UK, Wightman PD, Mukherjee AB: Uteroglobin inhibits phospholipase A2 activity. Life Sci 1986, 38(20):1813-9.

12. Yao XL, Levine SJ, Cowan MJ, Logun C, Shelhamer JH: Tumor necrosis factor-alpha stimulates human Clara cell secretory protein production by human airway epithelial cells. Am J Respir Cell Mol Biol 1998, 19(4):629-35

13. Lesur $\mathrm{O}$, Langevin $\mathrm{S}$, Berthiaume $\mathrm{Y}$, Legare $\mathrm{M}$, Skrobik Y, Bellemare JF, Levy B, Fortier Y, Lauzier F, Bravo G, Nickmilder M, Rousseau E, Bernard A: Outcome value of Clara cell protein in serum of patients with acute respiratory distress syndrome. Intensive Care Med 2006, 32(8):1167-74.

14. Bernard A, Carbonnelle S, Nickmilder M, de Burbure C: Non-invasive biomarkers of pulmonary damage and inflammation: Application to children exposed to ozone and trichloramine. Toxicol App/ Pharmacol 2005, 206(2):185-90.

15. Michel O, Murdoch R, Bernard A: Inhaled LPS induces blood release of Clara cell specific protein (CC16) in human beings. J Allergy Clin Immunol 2005, 115(6): 1143-7.

16. Bernard AM, Roels HA, Buchet JP, Lauwerys RR: Serum Clara cell protein an indicator of bronchial cell dysfunction caused by tobacco smoking. Environ Res 1994, 66(1):96-104.

17. Van Miert E, Dumont X, Bernard A: CC16 as a marker of lung epithelial hyperpermeability in an acute model of rats exposed to mainstream cigarette smoke. Toxicol Lett 2005, 159(2):115-23.

18. Arsalane K, Broeckaert F, Knoops B, Clippe A, Buchet JP, Bernard A: Increased serum and urinary concentrations of lung clara cell protein in rats acutely exposed to ozone. Toxicol Appl Pharmacol 1999, 159(3):169-74

19. Gowdy K, Krantz QT, Daniels M, Linak WP, Jaspers I, Gilmour MI: Modulation of pulmonary inflammatory responses and antimicrobial defenses in mice exposed to diesel exhaust. Toxicol Appl Pharmacol 2008, 229(3):310-9.
20. Mango GW, Johnston CJ, Reynolds SD, Finkelstein JN, Plopper CG, Stripp BR: Clara cell secretory protein deficiency increases oxidant stress response in conducting airways. Am J Physiol 1998, 275(2 Pt 1):L348-56.

21. Plopper CG, Mango GW, Hatch GE, Wong VJ, Toskala E, Reynolds SD, Tarkington BK, Stripp BR: Elevation of susceptibility to ozone-induced acute tracheobronchial injury in transgenic mice deficient in Clara cell secretory protein. Toxicol Appl Pharmacol 2006, 213(1):74-85.

22. Bochner BS, Busse WW: Allergy and asthma. J Allergy Clin Immunol 2005, 115(5):953-9.

23. Van Vyve T, Chanez P, Bernard A, Bousquet J, Godard P, Lauwerijs R, Sibille $Y$ : Protein content in bronchoalveolar lavage fluid of patients with asthma and control subjects. J Allergy Clin Immunol 1995, 95(1 Pt 1):60-8.

24. Laing IA, Hermans C, Bernard A, Burton PR, Goldblatt J, Le Souef PN: Association between plasma CC16 levels, the A38G polymorphism, and asthma. Am J Respir Crit Care Med 2000, 161(1):124-7.

25. Shijubo N, Itoh Y, Yamaguchi T, Sugaya F, Hirasawa M, Yamada T, Kawai T, Abe S: Serum levels of Clara cell 10-kDa protein are decreased in patients with asthma. Lung 1999, 177(1):45-52.

26. Hung $\mathrm{CH}$, Chen LC, Zhang Z, Chowdhury B, Lee WL, Plunkett B, Chen $\mathrm{CH}_{\text {, }}$ Myers AC, Huang SK: Regulation of $\mathrm{TH} 2$ responses by the pulmonary Clara cell secretory 10-kd protein. J Allergy Clin Immunol 2004, 114(3):664-70

27. Kuperman DA, Huang $X$, Nguyenvu L, Holscher C, Brombacher F, Erle DJ: IL-4 receptor signaling in Clara cells is required for allergen-induced mucus production. J Immunol 2005, 175(6):3746-52.

28. Reader JR, Tepper JS, Schelegle ES, Aldrich MC, Putney LF, Pfeiffer JW, Hyde DM: Pathogenesis of mucous cell metaplasia in a murine asthma model. Am J Pathol 2003, 162(6):2069-78.

29. Alessandrini F, Beck-Speier I, Krappmann D, Weichenmeier I, Takenaka S, Karg E, Kloo B, Schulz H, Jakob T, Mempel M, Behrendt H: Role of Oxidative Stress in Ultrafine Particle-Induced Exacerbation of Allergic Lung Inflammation. Am J Respir Crit Care Med 2009, 179(11):984-91.

30. Alessandrini F, Schulz H, Takenaka S, Lentner B, Karg E, Behrendt H, Jakob $\mathrm{T}$ : Effects of ultrafine carbon particle inhalation on allergic inflammation of the lung. J Allergy Clin Immuno/ 2006, 117(4):824-30

31. Su DS, Muller JO, Jentoft RE, Rothe D, Jacob E, Schlogl R: Fullerene-like soot from EurolV diesel engine: consequences for catalytic automotive pollution control. Topics in Catalysis 2004, 30-31(1-4):241-245.

32. Matuschek G, Karg E, Schroppel A, Schulz H, Schmid O: Chemical investigation of eight different types of carbonaceous particles using thermoanalytical techniques. Environ Sci Technol 2007, 41(24):8406-11.

33. Halatek T, Hermans C, Broeckaert F, Wattiez R, Wiedig M, Toubeau G, Falmagne P, Bernard A: Quantification of Clara cell protein in rat and mouse biological fluids using a sensitive immunoassay. Eur Respir $\rfloor$ 1998, 11(3):726-33.

34. Weibel E: Stereological Methods: Practical methods for biological morphometry Volume 1. London: Academic; 1979

35. Schwartz J, Slater D, Larson TV, Pierson WE, Koenig JQ: Particulate air pollution and hospital emergency room visits for asthma in Seattle. Am Rev Respir Dis 1993, 147(4):826-31.

36. de Haar C, Hassing I, Bol M, Bleumink R, Pieters R: Ultrafine carbon black particles cause early airway inflammation and have adjuvant activity in a mouse allergic airway disease model. Toxicol Sci 2005, 87(2):409-18.

37. von Klot S, Wolke G, Tuch T, Heinrich J, Dockery DW, Schwartz J, Kreyling WG, Wichmann HE, Peters A: Increased asthma medication use in association with ambient fine and ultrafine particles. Eur Respir $J 2002$, 20(3):691-702

38. Gangl K, Reininger R, Bernhard D, Campana R, Pree I, Reisinger J, Kneidinger M, Kundi M, Dolznig H, Thurnher D, Valent P, Chen KW, Vrtala S, Spitzauer S, Valenta R, Niederberger V: Cigarette smoke facilitates allergen penetration across respiratory epithelium. Allergy 2009, 64(3):398-405.

39. Morimoto $Y$, Ding L, Oyabu T, Hirohashi M, Kim H, Ogami A, Yamato H, Akiyama I, Hori H, Higashi T, Tanaka I: Expression of Clara cell secretory protein in the lungs of rats exposed to silicon carbide whisker in vivo. Toxicol Lett 2003, 145(3):273-9.

40. Cao Q, Zhang S, Dong C, Song W: Pulmonary responses to fine particles: differences between the spontaneously hypertensive rats and wistar kyoto rats. Toxicol Lett 2007, 171(3):126-37. 
41. Hay JG, Danel C, Chu CS, Crystal RG: Human CC10 gene expression in airway epithelium and subchromosomal locus suggest linkage to airway disease. Am J Physiol 1995, 268(4 Pt 1):L565-75.

42. Vilcek J, Lee TH: Tumor necrosis factor. New insights into the molecular mechanisms of its multiple actions. J Biol Chem 1991, 266(12):7313-6.

43. Finkelstein JN, Johnston C, Barrett T, Oberdorster G: Particulate-cell interactions and pulmonary cytokine expression. Environ Health Perspect 1997, 105(Suppl 5):1179-82.

44. Yamamoto S, Tin Tin Win S, Ahmed S, Kobayashi T, Fujimaki H: Effect of ultrafine carbon black particles on lipoteichoic acid-induced early pulmonary inflammation in BALB/c mice. Toxicol Appl Pharmacol 2006 , 213(3):256-66.

45. Lensmar C, Nord M, Gudmundsson GH, Roquet A, Andersson O, Jornvall $H$, Eklund A, Grunewald J, Agerberth B: Decreased pulmonary levels of the anti-inflammatory Clara cell $16 \mathrm{kDa}$ protein after induction of airway inflammation in asthmatics. Cell Mol Life Sci 2000, 57(6):976-81.

46. Aruoma Ol, Halliwell B, Hoey BM, Butler J: The antioxidant action of Nacetylcysteine: its reaction with hydrogen peroxide, hydroxyl radical, superoxide, and hypochlorous acid. Free Radic Biol Med 1989, 6(6):593-7.

47. Rahman I, MacNee W: Oxidative stress and regulation of glutathione in lung inflammation. Eur Respir J 2000, 16(3):534-54.

48. Moldeus P, Cotgreave IA: N-acetylcysteine. Methods Enzymol 1994 234:482-92.

49. Nie X, Li Q, Cai G, Dai Y, Zhang J: The effect of N-acetylcysteine on Clara cells and Clara cell $16 \mathrm{kDa}$ protein in a murine model of allergeninduced airway inflammation. Respirology 2005, 10(2):157-63.

50. Oberdorster $\mathrm{G}$, Utell MJ: Ultrafine particles in the urban air: to the respiratory tract--and beyond? Environ Health Perspect 2002, 110(8):A440-1.

51. Van Winkle LS, Evans MJ, Brown CD, Willits NH, Pinkerton KE, Plopper CG: Prior exposure to aged and diluted sidestream cigarette smoke impairs bronchiolar injury and repair. Toxicol Sci 2001, 60(1):152-64.

52. Evans MJ: Oxidant gases. Environ Health Perspect 1984, 55:85-95.

53. Stripp BR, Reynolds SD, Boe IM, Lund J, Power JH, Coppens JT, Wong V, Reynolds PR, Plopper CG: Clara cell secretory protein deficiency alters clara cell secretory apparatus and the protein composition of airway lining fluid. Am J Respir Cell Mol Biol 2002, 27(2):170-8.

54. Slutsky AS, Kamm RD, Drazen JM: Alveolar ventilation at high frequencies using tidal volumes smaller than the anatomical dead space. In Gas mixing and distribution in the lung Edited by: Engel LA, Paiva M. Marcel Dekker, Inc, New York, Basel; 1985:137-176.

55. Schulz H, Brand $\mathrm{P}$, Heyder J: Particle deposition in the respiratory tract. In Particle-lung interactions Edited by: Gehr P, Heyder J. Marcel Dekker, Inc, New York, Basel; 2000:229-290.

doi: $10.1186 / 1743-8977-7-11$

Cite this article as: Alessandrini et al., Effects of ultrafine particles-induced oxidative stress on Clara cells in allergic lung inflammation Particle and Fibre Toxicology 2010, 7:11

\section{Submit your next manuscript to BioMed Central} and take full advantage of:

- Convenient online submission

- Thorough peer review

- No space constraints or color figure charges

- Immediate publication on acceptance

- Inclusion in PubMed, CAS, Scopus and Google Scholar

- Research which is freely available for redistribution

Submit your manuscript at www.biomedcentral.com/submit
C BioMed Central 